PREPARED FOR THE U.S. DEPARTMENT OF ENERGY, UNDER CONTRACT DE-AC02-76CH03073

PPPL-3711

PPPL-3711

UC-70

ICRF Wave Propagation and Absorption in Plasmas with Non-thermal Populations

by

R.J. Dumont, C.K. Phillips, and D.N. Smithe

June 2002

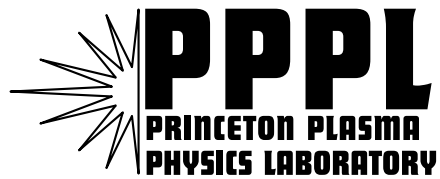

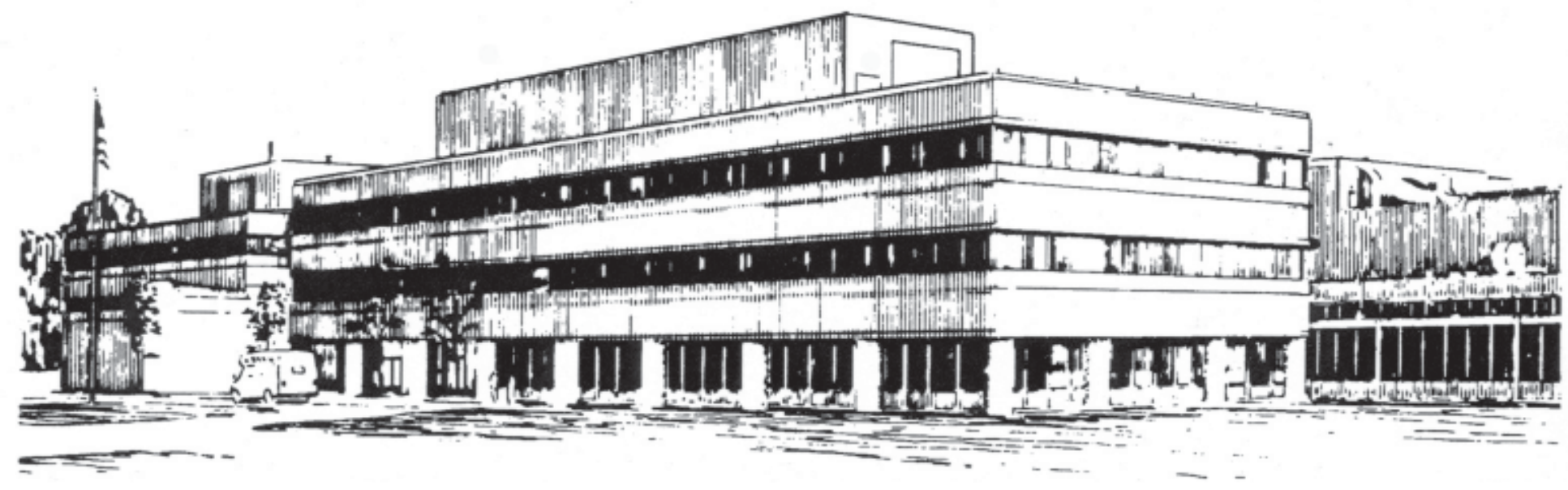

PRINCETON PLASMA PHYSICS LABORATORY PRINCETON UNIVERSITY, PRINCETON, NEW JERSEY 


\section{PPPL Reports Disclaimer}

This report was prepared as an account of work sponsored by an agency of the United States Government. Neither the United States Government nor any agency thereof, nor any of their employees, makes any warranty, express or implied, or assumes any legal liability or responsibility for the accuracy, completeness, or usefulness of any information, apparatus, product, or process disclosed, or represents that its use would not infringe privately owned rights. Reference herein to any specific commercial product, process, or service by trade name, trademark, manufacturer, or otherwise, does not necessarily constitute or imply its endorsement, recommendation, or favoring by the United States Government or any agency thereof. The views and opinions of authors expressed herein do not necessarily state or reflect those of the United States Government or any agency thereof.

\section{Availability}

This report is posted on the U.S. Department of Energy's Princeton Plasma Physics Laboratory Publications and Reports web site in Fiscal Year 2002. The home page for PPPL Reports and Publications is: http://www.pppl.gov/pub_report/

DOE and DOE Contractors can obtain copies of this report from:

U.S. Department of Energy

Office of Scientific and Technical Information

DOE Technical Information Services (DTIS)

P.O. Box 62

Oak Ridge, TN 37831

Telephone: (865) 576-8401

Fax: (865) 576-5728

Email: reports@adonis.osti.gov

This report is available to the general public from:

National Technical Information Service

U.S. Department of Commerce

5285 Port Royal Road

Springfield, VA 22161

Telephone: 1-800-553-6847 or

(703) 605-6000

Fax: (703) 321-8547

Internet: http://www.ntis.gov/ordering.htm 


\title{
ICRF wave propagation and absorption in plasmas with non-thermal populations*
}

\author{
R.J. Dumont ${ }^{1}$, C.K. Phillips ${ }^{1}$ and D.N. Smithe ${ }^{2}$ \\ ${ }^{1}$ Princeton Plasma Physics Laboratory, P.O. Box 451, Princeton, NJ 08543 (U.S.A.) \\ ${ }^{2}$ Mission Research Corp., Newington, VA 22122 (U.S.A.)
}

\begin{abstract}
Some results obtained with the one dimensional, all orders, full wave code METS, which has been successfully employed in the past to describe a number of experiments, are reported. By using massively parallel computers, this code has been extended to handle non-thermal populations. Various physical situations, in which non-Maxwellian species are expected to be encountered, are studied, such as simultaneous neutral beam injection and high harmonic fast wave electron heating or ion cyclotron resonance heating in the presence of fusion products.
\end{abstract}

In magnetic confinement fusion experiments relying upon externally driven waves in the ion cyclotron range of frequencies for auxiliary plasma heating, the target plasma is often characterized by the presence of non-thermal species. Non-Maxwellian ion populations can arise from neutral beam injection, from fusion reactions, or else from wavedriven acceleration of resonant ion species and may significantly alter the wave propagation and absorption properties.

Most wave field descriptions presented to date assume that the Finite Larmor Radius approximation is valid, which limits their range of application to low cyclotron harmonics and to modes with long wavelengths compared to the ions gyroradii. Recently, a new class of full-wave codes has appeared, which do not rely on this assumption [1-3].

The METS code, which is presented here, belongs to this class and has been extended to handle non-thermal populations. After a brief description of the code, the study of three physical situations will be presented, respectively in TFTR, NSTX and ITERFEAT, each being characterized by the presence of a non-Maxwellian population, owing to neutral beam ions, for the first two cases, or to fusion-produced alpha particles, for the latter. In this work, these non-thermal species will be described by isotropic slowing-down distributions [4].

\section{Description of the code}

METS is a one dimensional all-orders full wave code [2] which solves directly the Discrete Fourier Transform of the wave equation for the electric field

$$
\sum_{j} \exp \left(i k_{j} x_{i}\right)\left[(c / \omega)^{2} \mathbf{k}_{j} \times \mathbf{k}_{j} \times \overline{\overline{\mathbf{1}}}+\overline{\overline{\mathbf{K}}}\left(x_{i}, \mathbf{k}_{j}\right)\right] \cdot \mathbf{E}\left(k_{j}\right)=0
$$

*This work is supported by the U.S. DOE contract \#DE-AC02-76CH03073 
where $\mathbf{E}\left(k_{j}\right)$ is the Fourier transform of the electric field and $\stackrel{\overline{\mathbf{K}}}{\text { is }}$ the dielectric tensor kernel. $\overline{\overline{\mathbf{K}}}$ includes all orders in $k_{\perp} \rho_{L}$, where $k_{\perp}$ is the perpendicular wavenumber and $\rho_{L}$ is the ion Larmor radius. In other words, the code is able to handle situations in which either $\rho_{L}$ or $k_{\perp}$ becomes large. The implications of this feature are beyond the scope of this paper but are discussed extensively in ref. 5 .

Recently, METs has been extended to handle non Maxwellian distributions. In this

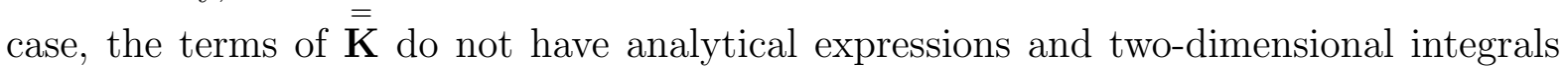
over velocity space must be performed numerically. Obviously, this implies a tremendous increase of the computational requirements and one has to resort to massively parallel computers to solve the problem within acceptable time and memory limits.

The new version of the code has been thoroughly benchmarked versus the original version, by comparing the results obtained using the analytical expressions for $\overline{\overline{\mathbf{K}}}$ and the results obtained with a numerical Maxwellian, where the velocity-space integrations are actually performed. Provided an adequate velocity space grid is used, it has been found that the results are generally indistinguishable.

\section{ICRH and NBI on TFTR}

On TFTR, Ion Cyclotron Resonance Heating has been extensively used to explore various aspects relevant to the Deuterium-Tritium reactor regimes [6]. A D-T shot is considered, with the following parameters: $B_{0}=4.7 \mathrm{~T}, n_{e 0}=4.7 \times 10^{19} \mathrm{~m}^{-3}, T_{e 0}=6.8 \mathrm{keV}$. In this discharge, the temperature of the present Deuterium, Hydrogen and Carbon ions was assumed to be $T_{i 0}=31 \mathrm{keV}$. A Tritium beam was injected in the plasma. The results obtained when this population is described by a slowing-down distribution and when an equivalent Maxwellian is used are compared, which is accomplished by computing an equivalent tail temperature at each radius. On figure 1(a) and 1(b), the power deposition profiles on electrons and Tritium ions, respectively, are shown for the two cases.
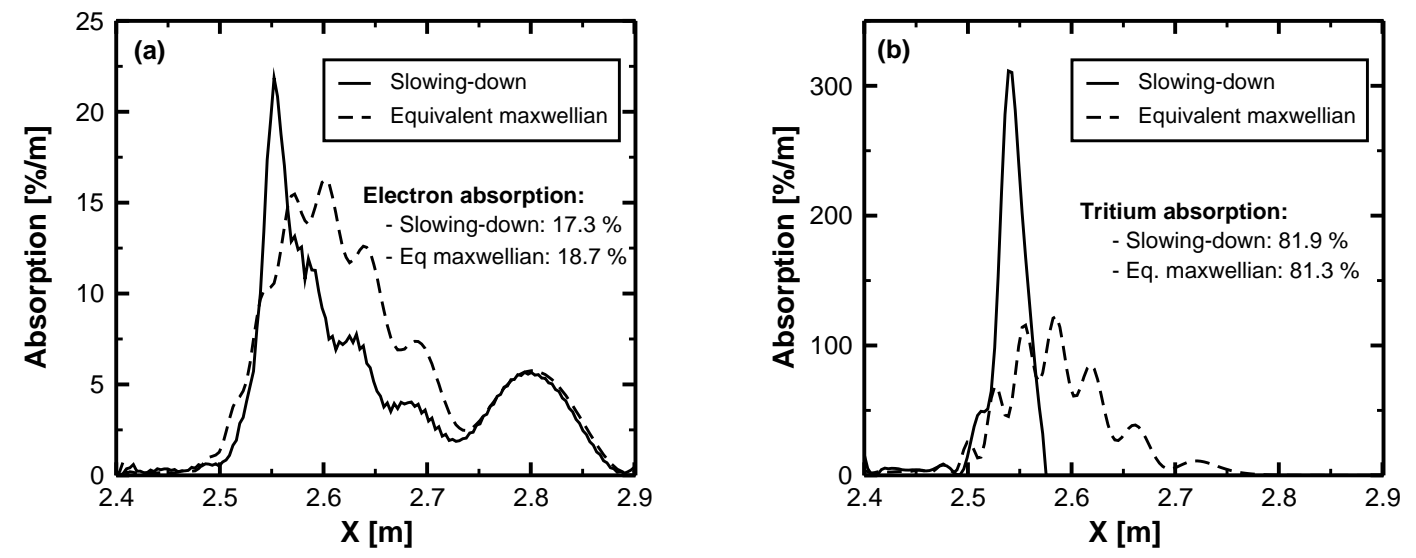

Figure 1: Power deposited on (a) Electrons, (b) Tritium when the latter are described by a slowing-down distribution (solid) or by an equivalent Maxwellian (dashed) in TFTR.

Although the net absorption is similar in both cases, the absorption profiles differ drastically, especially for the Tritium ions. When a slowing-down distribution function is used, the deposition profile appears to be much more peaked than for the equivalent Maxwellian. This point is still under investigation, but might be related to the presence of particles with an energy above $E_{\text {beam }}$ in the Maxwellian case, by contrast with the slowing-down distribution function, which imposes $f\left(E>E_{\text {beam }}\right)=0$. 


\section{HHFW and NBI on NSTX}

The spherical torus NSTX uses High Harmonic Fast Wave as a way to heat electrons and to drive non inductive toroidal current [7]. In the presence of Neutral Beam Injection, fast ions can eventually absorb a fraction of the wave power, which therefore can not be coupled to the electrons. We simulate a typical HHFW+NBI shot where $B_{0}=0.45 \mathrm{~T}$, $n_{e 0}=2.75 \times 10^{19} \mathrm{~m}^{-3}, T_{e 0}=1 \mathrm{keV}$. The wave frequency is $f_{F W}=30 \mathrm{MHz}$ and the launched parallel refractive index is $k_{\|}^{a n t}=14 \mathrm{~m}^{-1}$.

Deuterium, Hydrogen and Carbon ions are taken into account, all in thermal equilibrium with $T_{i 0}=1 \mathrm{keV}$. A back-of-envelope calculation indicates that the power is likely to be absorbed around the 8-th harmonic of the Deuterium. In addition, a Deuterium beam at $E_{b}=80 \mathrm{keV}$ is considered and modeled by a slowing-down distribution function.

Here, two situations are compared: in the first one, no beam is present, whereas in the second one the beam is taken into account. On figure 2(a), the left-handed electric field is shown in both cases, and the corresponding power depositions appear on figure $2(\mathrm{~b})$
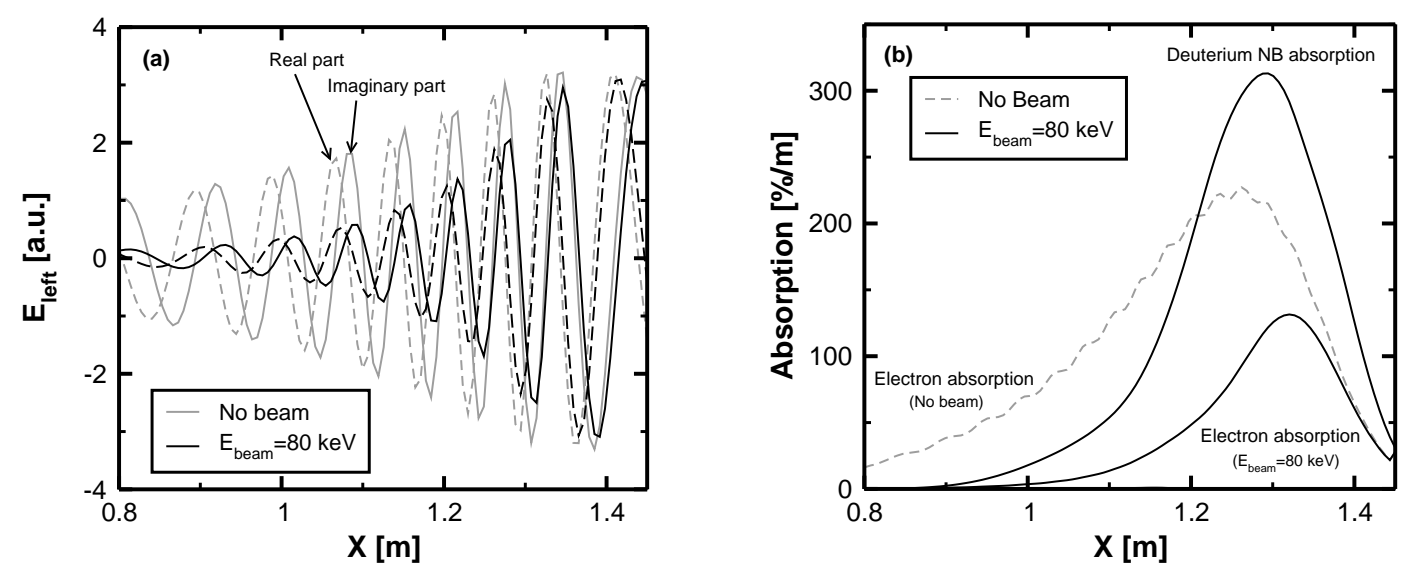

Figure 2: (a) Left-handed electric field, (b) Power deposition in the absence (grey), and in the presence (black) of a Deuterium beam at $E_{b}=80 \mathrm{keV}$ in NSTX.

The electric field is reduced when the beam is present, which indicates a stronger absorption of the wave. Indeed, the single-pass overall absorption increases from $70 \%$ to $94 \%$ when the beam is applied. Whereas in the first case, the electrons were entirely responsible for the power absorption, a large fraction of the power $(70 \%)$ is deposited on the beam ions, thus lowering the electron absorption which drops from $70 \%$ to $24 \%$. The deposition on other species $\left(\mathrm{H}\right.$ and ${ }^{6} \mathrm{C}$ ) is negligible, in both cases.

\section{ICRF on ITER-FEAT in the presence of fusion particles}

A prerequisite of the next-step experiments is high ion temperatures, at least for the reacting species. Among the various possible schemes, first harmonic Helium-3 minority heating has received a lot of interest [8]. To simulate this type of discharge in ITERFEAT, the following parameters are used: $R_{0}=6.43 \mathrm{~m}, a_{0}=2 \mathrm{~m}, B_{0}=5.2 \mathrm{~T}, n_{e 0}=$ $1 \times 10^{20} \mathrm{~m}^{-3}, T_{e 0}=25 \mathrm{keV}$. D, T, ${ }^{3} \mathrm{He}$ and ${ }^{6} \mathrm{C}$ ions are all taken to be thermal species with $T_{i 0}=20 \mathrm{keV}$. Both Deuterium and Tritium are assumed to have the same concentration $\left(\eta_{D}=\eta_{T}=42 \%\right)$ and $\eta_{H e-3}=3 \%$. Fusion produced Helium-4 ions are modeled by means of a slowing-down distribution characterized by $E_{b}=3.5 \mathrm{MeV}$ and $\eta_{\mathrm{He}-4}=0.6 \%$. In this simulation, the corresponding density was proportional to the electron density. The results of two calculations are presented, the first one neglecting alpha particles, the 
second one taken them into account. On figure 3, the absorption profiles are compared for both cases. For sake of clarity, the power depositions on $\mathrm{D}$ and on ${ }^{6} \mathrm{C}$, which are very low, do not appear. The corresponding absorption figures are summarized in table 1
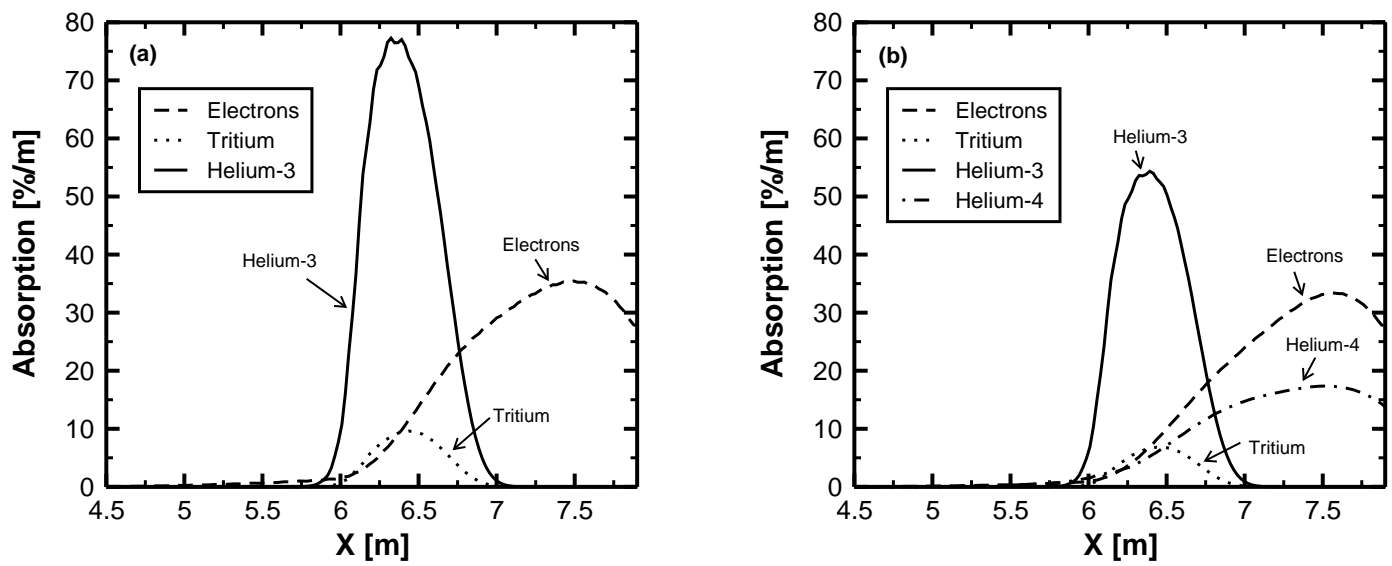

Figure 3: Power deposited on electrons (dashed), T (dotted), ${ }^{3} \mathrm{He}$ (solid) and ${ }^{4} \mathrm{He}$ (dashdots) ions in the absence (a) and in the presence of fusion alphas (b) in ITER-FEAT.

A significant fraction of the incident power is absorbed by the alpha particles, mostly to the detriment of the minority species. More simulations need to be performed with a narrower alpha density profile, however.

\section{Conclusion}

The all orders full-wave code METs is now able to describe the effects of non thermal populations in various heating schemes,

\begin{tabular}{c|c|c} 
& No alphas & Alphas incl. \\
\hline Electrons & $44.6 \%$ & $38.5 \%$ \\
Deuterium & $0.4 \%$ & $0.2 \%$ \\
Tritium & $5.3 \%$ & $3.8 \%$ \\
Helium-3 & $45.0 \%$ & $32.1 \%$ \\
Helium-4 & N/A & $22.7 \%$ \\
\hline Overall & $95.3 \%$ & $97.3 \%$
\end{tabular}
relevant to ongoing as well as to future experiments. As a first step, the results pre-

Table 1: Absorbed power in ITER-FEAT. sented here were all based on isotropic slowing-down distribution functions for the modeling of energetic ions. It should be emphasized, however, that METS is not restricted to this particular shape and in the short term, will handle arbitrary distribution functions so as to describe, for instance, the wave propagation and absorption in the presence of a strongly asymmetric RF tail.

\section{References}

[1] O. Sauter and J. Vaclavik, Nucl. Fusion, 32 (1992) 1455.

[2] D.N. Smithe et al., in Radio Frequency Power in Plasmas (AIP, NY, 1997), p. 367.

[3] E.F. Jaeger et al., Phys. Plasmas, 8 (2001) 1573.

[4] D.B. Batchelor et al., Phys. Fluids B, 1 (1989) 1174.

[5] D.N. Smithe, Plasma Phys. Control. Fusion, 31 (1989) 1105.

[6] C.K. Phillips et al.,Nucl. Fusion 40 (2000) 461.

[7] J.C. Hosea et al., in Proc. of the 28th EPS Conference on Contr. Fusion and Plasma Phys., 25A (2001) 1165.

[8] D. Van Eester et al., Nucl. Fusion, 42 (2002) 310. 


\section{External Distribution}

Plasma Research Laboratory, Australian National University, Australia

Professor I.R. J ones, Flinders University, Australia

Professor J oão Canalle, Instituto de Fisica DEQ/IF - UERJ , Brazil

Mr. Gerson O. Ludwig, Instituto Nacional de Pesquisas, Brazil

Dr. P.H. Sakanaka, Instituto Fisica, Brazil

The Librarian, Culham Laboratory, England

Library, R61, Rutherford Appleton Laboratory, England

Mrs. S.A. Hutchinson, JET Library, England

Professor M.N. Bussac, Ecole Polytechnique, France

Librarian, Max-Planck-Institut für Plasmaphysik, Germany

J olan Moldvai, Reports Library, MTA KFKI-ATKI, Hungary

Dr. P. Kaw, Institute for Plasma Research, India

Ms. P.J . Pathak, Librarian, Insitute for Plasma Research, India

Ms. Clelia De Palo, Associazione EURATOM-ENEA, I taly

Dr. G. Grosso, Instituto di Fisica del Plasma, Italy

Librarian, Naka Fusion Research Establishment, J AERI, J apan

Library, Plasma Physics Laboratory, Kyoto University, J apan

Research Information Center, National Institute for Fusion Science, J apan

Dr. O. Mitarai, Kyushu Tokai University, J apan

Library, Academia Sinica, Institute of Plasma Physics, People's Republic of China

Shih-Tung Tsai, Institute of Physics, Chinese Academy of Sciences, People's Republic of China

Dr. S. Mirnov, TRINITI, Troitsk, Russian Federation, Russia

Dr. V.S. Strelkov, Kurchatov Institute, Russian Federation, Russia

Professor Peter Lukac, Katedra Fyziky Plazmy MFF UK, Mlynska dolina F-2, Komenskeho Univerzita, SK-842 15 Bratislava, Slovakia

Dr. G.S. Lee, Korea Basic Science Institute, South Korea

Mr. Dennis Bruggink, Fusion Library, University of Wisconsin, USA

Institute for Plasma Research, University of Maryland, USA

Librarian, Fusion Energy Division, Oak Ridge National Laboratory, USA

Librarian, Institute of Fusion Studies, University of Texas, USA

Librarian, Magnetic Fusion Program, Lawrence Livermore National Laboratory, USA

Library, General Atomics, USA

Plasma Physics Group, Fusion Energy Research Program, University of California at San Diego, USA

Plasma Physics Library, Columbia University, USA

Alkesh Punjabi, Center for Fusion Research and Training, Hampton University, USA

Dr. W.M. Stacey, Fusion Research Center, Georgia Institute of Technology, USA

Dr. J ohn Willis, U.S. Department of Energy, Office of Fusion Energy Sciences, USA

Mr. Paul H. Wright, Indianapolis, Indiana, USA 
The Princeton Plasma Physics Laboratory is operated by Princeton University under contract with the U.S. Department of Energy.

\author{
Information Services \\ Princeton Plasma Physics Laboratory \\ P.O. Box 451 \\ Princeton, NJ 08543
}

Phone: 609-243-2750

Fax: 609-243-2751

e-mail: pppl_info@pppl.gov

Internet Address: http://www.pppl.gov 